\title{
UNIVERSO MÍTICO-RELIGIOSO KIMBUNDU E TRÂNSITOS CULTURAIS EM UANHENGA XITU
}

\section{Washington Santos Nascimento}

Universidade do Estado do Rio de Janeiro (Uerj), Rio de Janeiro - RJ, Brasil. E-mail: washingtonprof@gmail.com

DOI: $10.17666 / 329514 / 2017$

\section{Introdução}

Este artigo promove uma discussão sobre o universo mítico-religioso do interior angolano de finais do século XIX até meados do século XX, a partir da análise da obra Vozes na sanzala (Kahitu), publicada em 1976 pelo escritor angolano Wanyenga Xitu (Uanhenga Xitu na versão aportuguesada), também conhecido pelo nome português de Agostinho André Mendes de Carvalho. Importa-nos analisar de que forma aspectos mítico-religiosos desse universo banto (sobretudo AkwaKimbundu), como os "gênios da natureza" (kiandas e kitutas) e os sacerdotes (kimbandas e kilambas), transitam no cotidiano e imaginário social daquele espaço em transformação, por conta da chegada dos portugueses e de novas matrizes socioculturais cristãs.

Artigo recebido em 09/12/2015

Aprovado em 25/05/2017
AkwaKimbundu é como se autodenominam os povos que atualmente habitam as regióes de Luanda, Bengo, Cuanza Norte, Cuanza Sul e Malanje. Em kimbundu, Akwa quer dizer "os", "os de", "os pertencentes a”, e que, junto à palavra kimbundu, quer dizer "os falantes do Kimbundu", "os do Kimbundu" ou ainda "os pertencentes ao Kimbundu". Assim, neste artigo, usaremos AkwaKimbundu para nos referir a povo e Kimbundu quando nos referirmos ao complexo povo-língua-universo cultural. ${ }^{1}$

Vozes na sanzala pode ser entendido como uma memória social dos AkwaKimbundu, transmitido por um de seus "mais velhos", pois, como Xitu salienta, "cada um de nós, 'os mais velhos' que na nossa terra existem, resume em si a memória de centenas de anos. Cada dia mais rica, porque vivemos hoje mais tempo do que viviam os nossos avós" (Xitu, 2014 [1998], p. 18).

Sua história central é clássica nos estudos antropológicos e diz respeito à não observância de 
práticas rituais tradicionais (Akwakimbundu, banto) em um contexto de mudança cultural (presença dos portugueses e de missóes religiosas estrangeiras) e a consequente punição por esse ato (Kahitu nascera paralítico).

Assim, através dessa obra, podemos discutir de que maneira os AkwaKimbundu travaram o debate sobre a manutenção de categorias existentes antes da chegada dos europeus, em um contexto de transformações sociais e culturais, questionamento e redefinição da própria pertença. Entendemos que, mesmo em situação de grande contato, tal qual a Angola colonial de finais do século XIX até meados do XX, onde os portugueses dominavam os demais grupos existentes, havia alguns espaços de pertencimento dos grupos locais, sobretudo nos setores de atividade religiosa e doméstica. ${ }^{2}$

Wanyenga a Xitu nasceu em 29 de agosto de 1924, em Calomboloca, regiāo de Icolo-Bengo, interior de Angola, e faleceu com 90 anos, em 2014. A ida para as missóes e a necessidade de ter um nome português o fez ser renomeado como Agostinho André Mendes de Carvalho. Sua região de origem é de povos falantes do Kimbundu. Como escritor, adotou sempre o Uanhenga Xitu, uma variação em português de seu nome em Kimbundu, Wanyenga a Xitu. Xitu significa "carne”, já Wanyenga "pendurar, levar a carne”, e a somatória das palavras quer dizer "andar com a carne pendurada". Em entrevista dada em 2004, ele explica que usou essa alegoria para representar a maneira pela qual os dirigentes de uma aldeia ou de um país, por despertarem ódio ou inveja, sempre têm de andar com policiais, guarda-costas, carros etc. (a "carne pendurada"), e que, por essa razão, seria odiado; daí que, segundo ele, Wanyenga a Xitu significaria "o poder é odiado" (Xitu, 2004b).

Como escritor, produziu uma vasta obra literária: O meu discurso (1974), Mestre Tamoda (1974); Bola com feitiço (1974), Manana (1974), Vozes na sanzala (Kahitu) (1976), Maka na sanzala (1979), Sobreviventes da máquina colonial depóem (1980), Os discursos do Mestre Tamoda (1984), O ministro (1990) e Cultos especiais (1997). Isso o tornou responsável por contribuir para um processo de "angolanização" da literatura angolana, com a incorporação de elementos do Kimbundu falado na regiāo de Icolo-Bengo. Por essa razão, os diálogos de seus personagens são marcados pela "construção simples", "ritmada e sincopada das frases", sem estar "enclausuradas" na rigidez da semântica e da gramática portuguesa. Entretanto, ele diz que nunca foi seu objetivo "angolanizar" a língua portuguesa e que apenas escrevia o que achava que deveria ser escrito (Xitu, 1984b).

Xitu pode ser percebido como um intelectual em constante trânsito (tanto cultural como espacial), produzindo nos entrelugares da situação colonial. Ele dialogou com a tradição e a oralidade em seus escritos, objetivando trazer maior conhecimento e problematização da história de seu país, e teve um papel importante na resistência ao colonialismo português em Angola, na construção do Estado pós-independência e no processo de descolonizaçáo do conhecimento, mesmo utilizando a escrita europeia para isso. Como intelectual, Xitu teve a capacidade de dar corpo a uma mensagem para (e também por) um público específico, aqueles de origem Kimbundu. Da mesma forma, através de suas obras literárias, ele foi um mediador cultural entre os universos Kimbundu, citadino luandense e o europeu. Ao longo do tempo, transitou entre o papel de "mais velho", escritor, cientista social e político, perfazendo para tanto um jogo de exclusôes (um escritor que não se dizia político) e complementaridades (um "mais velho" que é também um escritor).

\section{Vozes na sanzala: tempo e escrita}

Vozes na sanzala se passa em dois momentos distintos, finais do século XIX e os anos de 1930 e 1940, no século XX, e conta a história de Kahitu, que nascera paralítico em uma povoação do interior angolano, área predominantemente AkwaKimbundu. Sua paralisia era associada a uma punição da kituta (um "gênio da natureza") para com seus pais (Mukita e Mbombo), por estes não terem feito uma obrigação devida pela avó dele (Kaualende) desde o século XIX. Kahitu estudara com os mestres tradicionalistas locais (mais propriamente o ferreiro) e um pouco nas escolas das missóes cristâs, por isso sabia ler e escrever cartas em português como ninguém na sua povoação rural de origem (a sanzala). 
Conhecido como "filho da kituta", vivia no ostracismo, só sendo reconhecido pelas crianças como um mestre das brincadeiras infantis e pelas mulheres jovens a quem dava alguns conselhos sobre namoros e casamentos. É por uma dessas jovens que ele se apaixona, a bela Saki, passando a cortejá-la, mesmo sendo ele considerado um inválido ("aleijado”) pelo seu grupo social. Após ter relação sexual com Saki, a engravida, conseguindo dessa forma provar a sua virilidade perante o grupo. Entretanto, tal fato também causa um grande estranhamento e revolta em seus pares: ele é entáo chamado pelos sobas (chefes tradicionais) locais para ser julgado pelo acontecido. Como um ato de resistência a essa convocação, Kahitu se suicida com veneno de gafanhoto. Após sua morte, uma chuva torrencial com muitos raios e trovões se abate sobre a sanzala, e permanecerá por anos. Esse suposto castigo da kituta sobre os moradores locais, por terem provocado a morte de "seu filho", atingirá Saki e o feto, também mortos por raios.

Akiz Neto (2010) levanta a hipótese de que, por ter sido enfermeiro, Xitu ouvira muitas histórias contadas por mães de crianças acometidas por poliomielite, razão por que desenvolviam certas deficiências físicas. Algumas dessas mães acreditavam que essas deficiências seriam uma punição da "kituta/sereia" aos seus familiares. Teria sido este entâo o mote a partir do qual Xitu teria desenvolvido a história de Kahitu.

Essa obra foi escrita quando o autor estava preso. Segundo Xitu (2004b, p. 65), o livro, "foi uma das amigas íntimas e fiéis do meu longo cativeiro [...] constituíram, para mim, a base íntima, pessoal, dando-me forças para resistir, resistir até a liberdade". Assim, voltar ao passado, às brincadeiras infantis, ao contato com a natureza (física e mítica), e, por fim, ao mundo tradicional e às suas raízes era uma forma de manter a sanidade naquele contexto extremamente difícil.

Em um depoimento, Xitu (2014 [1998], p. 18) diz que, durante o período em que passou na cadeia, "começava a pensar nos tempos da minha terra. Naquilo que eu tinha vivido e naquilo que eu tinha escutado da boca dos meus 'mais velhos". Sua fala assume, assim, a dimensão de uma memória social (Fentress $e$ Wickham, 1992) de seu grupo de origem, uma "urgência do recordar" para superar a "inevitabilidade do esquecer" em um período de forte contato e mudança decorrente da presença portuguesa (Fonseca, 2010).

Enquanto memória social dos AkwaKimbundu, Vozes na sanzala pode ser entendido como uma oratura (literatura oral), ou seja, produto de um acervo de histórias trazidas da tradição oral e registradas sob a forma da escrita. Kahitu fazia parte das histórias que se "contavam no antigamente", como uma forma de enaltecer uma divindade, em um contexto no qual as "imposiçôes das igrejas" já faziam parte do cenário, afinal era preciso saber "de onde nós viemos antes da igreja e da luta entre a igreja e a nossa população" (Xitu, 2004b, p. 217). Trata-se, dessa forma, de uma maka, ou seja, uma história verdadeira (ou reputada como tal), porém com um final instrutivo e útil (Macedo e Chaves, 2007).

\section{Espaço e geografia literária de Vozes na sanzala}

Sanzala, como já dissemos, é o nome dado em Kimbundu a uma povoação rural angolana, como uma aldeia, por exemplo. Nas obras de Xitu, quase sempre ela está situada na regiáo de Icolo-Bengo, às margens do rio Cuanza ou Bengo, ou, mais especificamente, "ali nas sanzalas de Madimu, de Cajú, Jinganga, Cassenda, Quilende, Quizenza, Ngala, Cabiri e Funda" (Xitu, 2004c, p. 65), espaços privilegiados de sua geografia literária, entretanto próximos e sob a influência cultural de Luanda. Toda essa região que vai de Malanje até Luanda era habitada pelos AkwaKimbundu, que, desde pelo menos o século XVI, viviam da agricultura e se organizavam em aldeias.

A presença portuguesa na região data de 1492, quando Diogo Cáo desembarcou na foz do rio Zaire. Da segunda metade do século XIX até o início do século XX, segundo Jill Dias (1994), ela já estava profundamente consolidada, levando à mudança na composição étnica da população local, provocada pelo influxo de cativos de variadas zonas do interior angolano e da miscigenação dos autóctones com os portugueses e com a cultura europeia. 


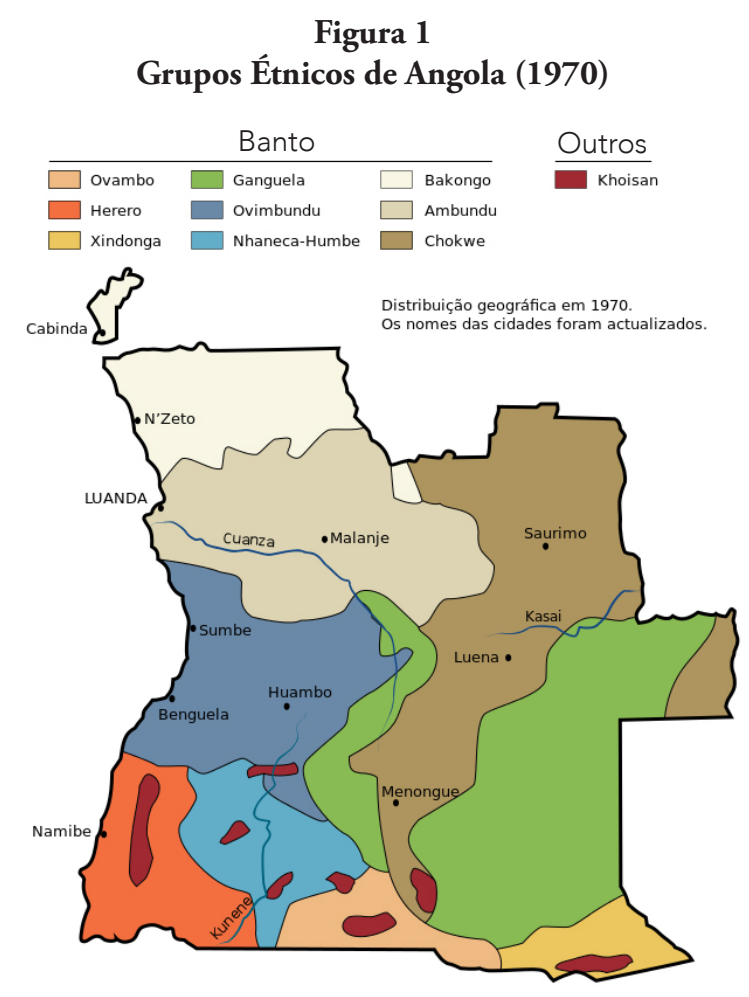

Fonte: Pélissier (1978).

No início do século XX, as novas exigências do comércio ultramarino português, a expansão colonial e também demográfica, com o aumento da comunidade de comerciantes brancos na regiáo, transformaram profundamente a organização social, política e econômica Akwakimbundu, com a dissolução das formas tradicionais de autoridade e a perda de autonomia social e econômica, fazendo com que, entre os anos de 1875 e 1920, o controle político das relações de produção passasse das mãos dos chefes locais (antigos sobas) para fazendeiros, negociantes e oficiais coloniais portugueses (Dias, 1994).

Além dos portugueses, a região também foi marcada pela presença de missionários metodistas estrangeiros (sobretudo estadunidenses), que se instalaram entre Luanda e Malanje (de língua Kimbundu), desde 1885. O impacto das missóes não se limitou apenas à construção de igrejas, conversão da população ou mesmo à tradução da bíblia para as línguas africanas, foi além. As missões experimentaram o cultivo de novos produtos agrícolas, ensinaram ofícios como os de gráfico, alfaiate, pedreiro e carpinteiro, e promoveram o comércio, a alfabetização e o ensino do tipo ocidental. Assim, suas ações tiveram efeito duradouro sobre a população local, ocasionando modificaçôes na organização comunitária, nos processos de escolarização, formação para o trabalho, comportamentos e expectativas pessoais; além disso, estabeleceram novas redes de contato inter-regionais e mesmo internacionais (Conceição Neto, 2003).

Esses trânsitos propiciados pela chegada dos portugueses e das missóes religiosas estrangeiras foram provocados (e acentuados ao longo dos anos) pela existência de um corredor, desde o século XIX, por onde os produtos oriundos de regióes a leste (Moxico, Lundas etc.), tais como a cera, o marfim e a borracha, chegavam aos mercados coloniais do litoral (Luanda e Ambriz). Já no século XX, a linha de ferro de Benguela conectava parte dessas regióes. Aliás, as estradas férreas foram um elemento fundamental de colonização e penetração econômica portuguesa no interior, que permitiu o desenvolvimento tanto das quatro cidades do planalto - Malange, Nova Lisboa (atual Huambo), Silva Porto (atual Cuíto) e Sá da Bandeira (Lubango) - como de dois dos principais portos angolanos: Lobito e Moçamedes (Dias, 1994).

Assim, podemos entender esse espaço como o de um lugar de trânsitos e passagens. O próprio Xitu ressalta, em Vozes da sanzala, que, no início do século XX, os contemporâneos de Kahitu faziam da sanzala um lugar de transição, de onde partiam para trabalhar ou estudar fora de seus domínios, à exceção do protagonista, que sempre permanecera no local. Trata-se, assim, de uma zona de contato, ou seja, um espaço social onde "culturas díspares se encontram uma com a outra, frequentemente em relações extremamente assimétricas de dominação e subordinação - como o colonialismo, o escravismo, ou seus sucedâneos" (Pratt, 1999, p. 31).

Kahitu, tal qual Xitu, transitava entre o universo AkwaKimbundu e o português, estava nos "entrelugares" da relação entre os nativos e os europeus, ora sendo educado nos moldes tradicionais (o ferreiro), ora nas escolas missionárias. Mas, por nunca ter saído da sanzala, se tornara um tradicionalista e genealogista, conhecendo as raízes das famílias e seus segredos. 
Figura 2

Mapa de Angola com Destaque para as Regióes Kimbundu Descritas por Xitu em Vozes na sanzala

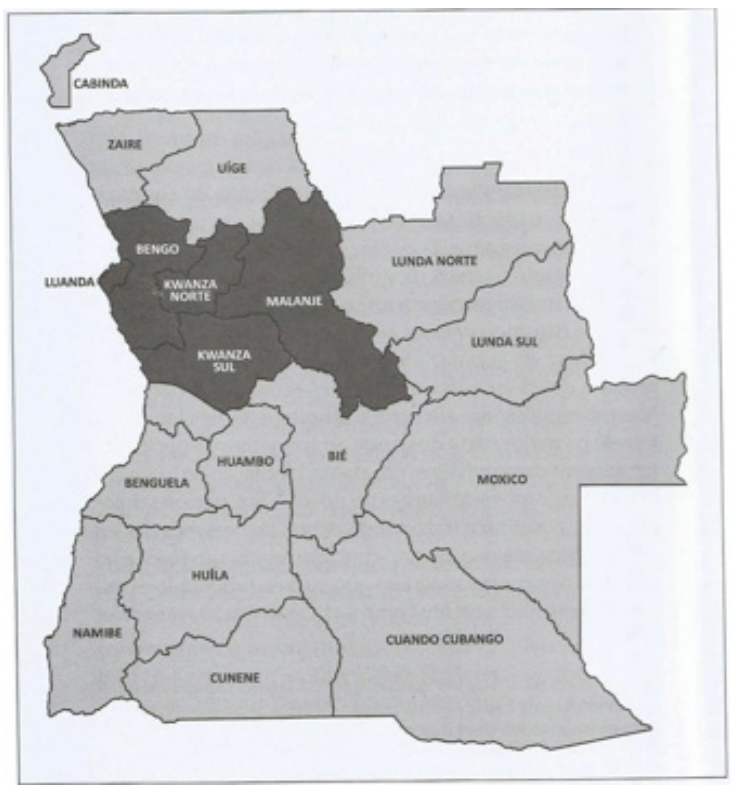

Fonte: Coelho (2010).

\section{Kitutas, kimbandas e kilambas no final do século XIX}

O livro começa relatando o nascimento de Kahitu, quarto filho de Mukita e Mbombo. Kahitu nascera paralítico e seus pais estavam preocupados, procurando kimbandas de todas as localidades para encontrar a cura, e nada, até aquele momento, tinha dado certo. Para tentar explicar o que de fato aconteceu, o narrador se volta para a história da avó materna de Kahitu, Kaualende, que se passa em finais do século XIX e nos oferece elementos importantes para entendermos aspectos do universo mítico-religioso Akwakimbundu.

Kaualende, avó de Kahitu, grávida, foi à fonte de água Kasadi em uma madrugada (horário não usual), invadindo, dessa forma, um espaço sacralizado e sob o domínio de um "gênio da natureza". No caminho, ouvira o canto do kabirindjindu, um pássaro lendário. Depois encontrou outro, o kingunguaxitu (grande pássaro do mato), que cantava pressagiando que algo ruim estava por vir. São eles que vão marcando os passos da avó de Kahitu até o encontro com o ser encantado, evidenciando, as- sim, a construção de um espaço complexo e múltiplo, onde o encantado e o terreno, o visível e invisível, interagem e se complementam. $\mathrm{Na}$ fonte, logo que acabou de encher o pote, quando ia levantar a panda (tecido usado para se proteger, mas também para fixar o pote), um vozeirão atrás de Kaualende diz:

- Eme Kasadi ka-ngi-telami kalaji.

[Eu sou a sereia de Kasadi; para mim, não admito intrusas de madrugada.]

- Em seguida, um som especial de sinos começou a ecoar, melodiosamente.

Assustada, Kaualende virou-se e deparou com um vulto humano, alvo como a neve. De cabelos compridos que lhe caíam até as costas. Ela caiu (Xitu, 2004c, p. 76).

Kiandas e kitutas são gênios da natureza, pertencem ao imaginário Kimbundu e não podem ser confundidas com as sereias, mito ocidental criado a partir da tradição greco-romana. Entretanto, percebe-se que, em sua obra, Xitu incorpora a denominação sereia como um sinônimo de kituta, demonstrando um entrelaçamento entre os universos locais e europeus, e a incorporação, por parte dos primeiros, de denominações (imaginários e valores) do colonizador europeu, trazidos, sobretudo, pelos missionários cristãos. De acordo com Peter Geschiere (2006), em suas análises sobre feitiçaria e modernidade nos Camarões, os novos imaginários ligados a feitiçaria não expressam apenas algum tipo de saudade por um passado dito tradicional. Pelo contrário, sua própria ambiguidade, que expressa ao mesmo tempo o "horror" e a "fascinação" pelas novas oportunidades que surgiam, ressalta o esforço despendido para lidar com as mudanças modernas. Por essa razão, esse discurso se torna elástico, buscando dessa forma capturar elementos novos introduzidos de fora (Geschiere, 2006, pp. 28-29), o que, a nosso ver, ocorre com a ideia das sereias.

Além disso, por ser uma obra literária, escrita em português e para um público leitor em sua grande maioria não AkwaKimbundu, fazia-se necessário usar um símbolo que pudesse ser compreendido por esse público mais amplo. As populaçóes locais associarem kituta (mas também as kiandas e 
kiximbis) às sereias era uma forma de traduzir um símbolo local para um universo ocidental, e assim ter êxito na intenção inicial de disseminar (entre os de origem europeia) o respeito por esse "gênio da natureza".

Kianda (plural ianda) era a nomenclatura do gênio existente na região do rio Cuanza, que banha a cidade de Luanda. À medida que o rio entra no interior de Angola, ela recebe a denominação de kituta e kiximbi, este último um termo mais antigo e pouco usual no século XX. A leitura de Vozes na sanzala nos sugere a existência dessa distinção, que não é só uma questão de nomenclatura, mas sim de tipos de organizaçáo social: de um lado, uma sociedade de pescadores (às voltas com o mar e kiandas), e, de outro, agricultores (com os rios, lagos e kitutas).

A descrição física da kituta feita por Xitu não se afasta de outras representaçóes de sereia no continente africano, e mesmo no espaço diaspórico, onde ela recebe nomes como Yemanjá, Janaína, mãe-d'água etc., e nos sugere que, em meados do século XX, a influência das representações europeias (no caso específico, uma sereia) já tinha sido incorporada e tomada para si como pertencente também do imaginário dos Kimbundu, ou seja, aquilo que em um primeiro momento era uma forma de tradução, torna-se, então, um elemento novo e local.

O contato de Kaualende com a kituta, sob a forma de sereia, provocou uma reaçáo com o espaço natural, evidenciando a interação entre a dimensão visível e invisível do mundo:

Os fetos frondosos e exuberantes que enchiam quase toda a baixa, com mais de um quilômetro de comprimento, faziam acenar as folhas. $\mathrm{O}$ mesmo imitavam os esguios coqueiros e palmeiras, as goiabeiras, as mafumeiras, as bananeiras e as mais diversas árvores e plantas. Os macacos guinchavam e faziam pulos acrobáticos, nunca antes vistos por qualquer homem. Próximo do corpo da Kaualende, levantavam-se três compridas palmeiras, sobre as quais andava um felpudo esquilo, muito irrequieto. "Cantava", mas um "cantar" estridente (Xitu, 2004c, p. 76).
Xitu diz, entâo, que, quando a kituta aparecia, tudo se movimentava, todos os seres do universo vegetal e animal, todos a respeitavam, porque senâo ela secava a água do manancial. Percebe-se um mundo complexo e interligado, onde diferentes dimensôes do visível e do invisível se entrelaçam e se complementam. Achada desacordada, Kaualende é levada para casa, onde passa a ser tratada por uma série de kimbandas.

O kimbanda (ou quimbanda, em português) era o responsável pelos processos de cura, conhecendo para tanto as propriedades e aplicaçóes das plantas. Como se acreditava que os males tinham sempre causas sobrenaturais, tais como enfeitiçamento, vingança, contrariedade etc., o kimbanda fazia uso da adivinhação como parte de seu diagnóstico. Por outro lado, tinha um caráter duplo, podendo, em alguns casos, assumir um papel de feiticeiro e, assim, fazer uso do feitiço para matar ou mesmo atrapalhar a vida de uma pessoa.

Não há, em Vozes na sanzala, uma descrição mais pormenorizada do kimbanda. Entretanto, ele é um personagem central em diferentes obras de Xitu, destacadamente em Maka na sanzala, de 1979. Construído a partir das suas memórias e experiências pessoais, mesmo sob estruturação e convençôes próprias de uma obra literária, oferece-nos um rico painel dos procedimentos de duas quimbandas no auxílio a um parto difícil. A primeira, denominada apenas como "velha quimbanda", ao encontrar-se com a mulher em trabalho de parto:

Fazia das suas mãos kixakatu. Os dedos da mão direita passava-os na palma da mão esquerda, como quem estivesse a afiar uma navalha. Deslizava-os com uma destreza de impressionar. Dessa sua perícia mágica saíam uns estalidos singulares. De vez em quando tirava de uma pasta de couro uns pós brancos que atirava para trás e para a frente de si, ao mesmo tempo que monologava umas preces (Xitu, 2004c, p. 21).

Chega, entáo, outra quimbanda (Kasexi), a mais importante da região - e a única que, ao tocar seus guizos, fazia os moribundos abrirem os olhos ou mexerem os lábios -, para terminar de auxiliar no parto. Xitu assim descreve as açôes de Kasexi: 
De repente a velha quimbanda, num movimento diabólico, urrou e buibuilou, mexendo-se convulsivamente, ao mesmo tempo que sacudia os sinos que the pendiam dos paramentos. E esteve neste delírio por longos minutos [...] Nada mais aconselhou senão tirar uns pós mágicos da sua bolsa. E deitou uma pitada de pós na língua da Mulemba. Da mesma forma "sacou" um boião de onde tirou uns pós e fez uns riscos cabalísticos em volta da cabeça e da cintura do bebê (Xitu, 2004c, p. 35).

Nas duas descrições, destaca-se o uso de pós brancos no trabalho de parto. Mariana Fonseca (2015) registra que, desde o século XVII, os povos dessa regiáo usavam a pemba, um pó branco sagrado, feito de argila, em rituais que visavam garantir a fertilidade feminina e a reproduçáo do grupo, e utilizavam também a takula, pó feito da árvore de mesmo nome, nos rituais masculinos. Em seu dicionário de termos angolanos, Oscar Ribas diz que a pemba era um "calcário margoso", um caulim (espécie de gesso), que possuía largo emprego na umbanda, "servindo, juntamente com o ucusso, para as caracterizaçóes que, obrigatoriamente, se executam nos lugares concernentes à liturgia, a fim de se abrirem os caminhos, ou seja, para atrair a graça dos espíritos” (Ribas, 2009 [1969], p. 317-318).

Como dissemos, o kimbanda poderia assumir o papel de feiticeiro, apenas o trabalho era diferente. Na obra de Xitu, Os discursos do Mestre Tamoda, de 1984, a portuguesa Dona Amélia gostaria de separar sua filha do "preto" Marajá, por isso pede a seu cozinheiro para procurar um kimbanda. Depois de voltar do primeiro contato com este, perguntou o funcionário à sua senhora: se era para "virar o coração da menina" ou "matar o rapaz no feitiço" (Xitu, 1984a, p. 132).

Voltando a Vozes na sanzala..., se conclui que somente outro tipo de sacerdote, um kilamba, poderia ajudar Kaualende. O kilamba era o intérprete das kitutas, o único que podia conversar com elas, tratar das enfermidades ocasionadas por esses gênios da natureza, usando, para isso, também a adivinhação como diagnóstico. Foi a kituta ou não? Se foi a kituta, por que foi?
No apêndice de Vozes, Xitu define o kilamba como sendo ligado às "sereias", responsáveis por tratar e curar as doenças relacionadas com elas, bem como, eventualmente, pela consagração dos sobas em suas cerimônias de coroação. Eles já nasciam predestinados, trazendo do ventre da mãe um sinal característico que só os entendidos sabem reconhecer nos primeiros dias de vida. Além disso, era consagrado ("feito") de forma diferente dos kimbandas, tendo ritos próprios.

A origem dos kilambas é associada ao poder dos antigos Ngola. Beatriz Heintze (1998) conta que o Ngola que reinava em 1575 no Estado do Ndongo - que cobriu parte significativa dos territórios Kimbundu -, afirmava ser um kilamba, portanto senhor do sol e da chuva, estando dessa forma ligado à fertilidade da terra e ao bem-estar de seus governados. Mais recentemente, o primeiro presidente de Angola pós-independência, Agostinho Neto, designava-se, desde a luta colonial, como kilamba, uma forma de se fazer entender entre as comunidades tradicionais como um chefe e/ou presidente (Coelho, 2010).

Oscar Ribas (2002, p. 66) acrescenta que esses sacerdotes eram os responsáveis por cuidar da cólera da sereia "quer embravecendo o mar ou qualquer outro curso de água, bem ainda as infestaçóes de feras e a estiagem". Como as sereias, os kilambas podiam ficar embaixo da água até um mês. Tal qual Xitu, Ribas (2002) diz ainda que normalmente um kilamba tinha alguma deformação física, mas que somente um kimbanda poderia revelar a essa pessoa se ela seria ou não um kilamba. Assim, podemos ao menos supor que Kahitu um dia poderia ter-se tornado um kilamba.

$\mathrm{Na}$ conversa do kilamba com o pai de Kaualende, estabelece-se um debate entre as antigas tradiçóes Kimbundu (e banto) e os novos elementos religiosos (e culturais) trazidos pelos europeus naquele contexto:

- Há muito venho despertando a essa gente de que era tempo de se oferecer um banquete ao Kasadi. Mas... A água está a diminuir, já não chega lá ao fundo, na lavra do Kingolo; os desdéns já não tem o mesmo gosto e nem produzem o óleo como antigamente; há dias, uma 
cobra preta e cheia de cabelos correu atrás de mulheres que iam buscar água, escapando matar o filho de Kinguadi, e não falemos na jiboia que engoliu o cão de Kaiambi, agora surge este caso da tua filha! Não teríamos evitado tudo isso se o povo ouvisse os meus conselhos?...

- Ah, meseneKilamba - interrompeu um dos velhos presentes, hoje é escusado, os nossos filhos não ligam a essas coisas. Vieram os homens da Missão...

- E que desrespeito, cantam e assobiam atrevidamente os hinos da Missão, mesmo quando estão a tomar banho nas águas do NganaKasadi! - disse um outro velho, num tom de muito aborrecido. (Xitu, 2004c, p. 74)

O Kasadi era o nome da fonte (uma espécie de lago), onde a "sereia" aparecia. Tratava-se de entidades encantadas que tinham o poder da metamorfose, transformando-se em cobras, por exemplo. Essa era também uma forma de provar, naquele contexto mais racional, a presença física das antigas tradições.

Xitu também revela os impactos das missóes cristãs na região, responsáveis por novos ordenamentos religiosos e culturais. Se, por um lado, as igrejas protestantes (e mesmo católicas) podiam ser uma resposta às grandes inquietaçóes do encontro e desencontro colonial, podiam ser também razão de inquietação, pois, apesar de suas diferenças, que vão desde a relação com o poder metropolitano até o ethos religioso, católicos e protestantes compartilhavam a mesma visão de que o africano deveria ser salvo pelos cristáos e de que o que havia antes da chegada dos europeus náo passava de crendices ou selvageria (Paredes, 2010).

Voltando a Vozes na sanzala, a situação se resolve após o pai de Kaualende realizar o mais pomposo banquete que um kilamba já tinha preparado até então para uma kituta. Victor Turner (2005), em seus estudos sobre os Ndembu, povos do noroeste da Zâmbia (país vizinho a Angola), diz que a escolha por realizar determinados rituais que não estavam diretamente ligados ao calendário geral do grupo social ocorria em momentos de crise daquela comunidade, servindo, dessa forma, como uma tentativa de retorno ao equilíbrio espiritual de um indivíduo ou mesmo do grupo que foi perturba- do por alguma "anomalia", como a infertilidade de uma mulher ou o nascimento de gêmeos. No caso em questão, a "anomalia" era o fato de Kaualende ter invadido um espaço sagrado em uma hora imprópria sem a permissão da kituta.

José Redinha (1975 registra que, em Luanda, região próxima à descrita por Xitu, organizavam-se suntuosos banquetes para os gênios da natureza (as sereias, na sua descrição), com louças, vinhos doces, pentes e iguarias africanas junto com outras europeias. Segundo ele, dispunha-se esses objetos em esteiras, na praia, após o que toques de tambor anunciavam à sereia que o banquete seria servido.

Ao acordar, Kaualende dá mais detalhes do encontro com a kituta, revelando, assim, a circularidade da história, um recurso da maka, a forma tradicional que Xitu escolheu para escrever a sua obra literária, distante, assim, da linearidade mais comum nos contos europeus.

Pelo caminho encontrei-me com um kingunguxitu muito grande! Fez-me assustar. O coração pesou-me, mas resolvi ir até a nascente. Posta lá, ouvi cantar outro kingungu, parecia persuadir-me para não avançar. Mas como a interpretação do cantar daquele pássaro é considerado como brincadeira de crianças, embora seja envolvida a muitas lendas, não liguei... Quando enchi a sanga, comecei a ouvir um som de guizos. Pensei que fosse uma pessoa vestida de mandungela (sinetas, guizos) e que ia a um xingidi (xinguilador “médium”). Logo que endireitei a disanga já cheia ouvi alguém a dizer: Eme kasadi ngitelami kalaji (Eu sou a sereia de Kasadi, não admito intrusas na madrugada) (Xitu, 2004c, p. 83).

Kaualende segue detalhando o encontro com a kituta, descrita por ela como "branca como o fubá de kindele (milho)", e que só a vira sob a forma de sereia, da cabeça à cintura, "estava ajoelhada na água, e tinha-me dado as costas. O cabelo comprido e molhado, colava-se-lhe às costas" (Xitu, 2004c, p. 84). Em uma perspectiva ampla para os povos da região Congo-Angola, o mundo estava dividido em duas esferas, a dos vivos/terrenos e a dos mortos/encantados; estes últimos tinham a cor branca e eram os ancestrais daqueles que fundaram 
as aldeias e organizaçóes políticas (Costa e Silva, 1998). No livro Os discursos do Mestre Tamoda, de 1984, Xitu relata a história de José Maquita, "preto, beçula" que morava em Portugal desde pequeno e, ao voltar para Angola, trouxe a sua esposa e a apresentou aos pais no interior. Assustados com a cor da mulher, seus progenitores fugiram, dizendo que o filho lhes havia trazido uma kianda.

Depois da fala de Kaualende, um novo ritual foi feito, não só pelo kilamba, mas também pelos kimbandas que estavam no local, com o oferecimento de bebidas ritualizadas, toque de guizos e danças. A partir daquele encontro (e da primeira obrigação feita), Kaualende e toda a sua geração serviriam à kituta, ou seja, em toda festa ou invocação a ela, deveria fazer-se presente a família de Kaualende e seus descendentes. Além disso, em toda gravidez se faria uma obrigação para a "sereia", pois senão o filho nasceria com alguma deformação.

Assim, Mbombo, filha de Kaualende e mãe de Kahitu, nascera saudável e já sabendo das obrigaçôes que tinha para com a "sereia". Ao se casar com Mukita, cumprira, dedicadamente, esse seu compromisso com os quatro primeiros filhos, menos com o último, Kahitu. E, talvez por essa razáo, este nascera com uma deficiência física.

Depois disso a história dá um salto para os anos de 1930-1940.

\section{O filho da Kituta e a vingança do gênio da natureza (século XX, anos de 1930-1940)}

$\mathrm{Na}$ continuação da história, nos anos de 19301940, Kahitu está com 15 a 16 anos. Deficiente que era, arrastava-se pela sanzala, tinha uma grande vontade de aprender a ler e a escrever e era muito afamado com as crianças mais novas, sendo o "mestre" das brincadeiras. Apesar de um pouco crescido, continuava na sanzala, já que sua deficiência o limitava para ir tanto à escola da missão, nas aldeias vizinhas, quanto ao trabalho braçal.

Quando um professor chegou à sanzala, Kahitu já sabia ler em português, autodidata que era, sendo por isso o seu melhor aluno. Mas a turma logo seria desmontada e ele ficaria mais uma vez sem escola, dedicando-se, então, a fazer parte da oficina de um velho ferreiro, ajudando-o na confecção de facas, machados, catanas, agulhas, arpóes, chuços e enxadas. Competia a Kahitu manejar o fole, tocando batuque com o uso desse instrumento, fazendo da oficina não só um espaço de confecção de materiais, mas também um espaço de música e dança: a itonda e o kalembe, uma dança regional exclusiva das mulheres.

Diferentemente de seus contemporâneos, Kahitu permanecera na sanzala desde que nascera e, por essa razão, se tornara um grande genealogista, ou seja, quem quisesse saber dos ascendentes de determinada família, recorria a seus conhecimentos. Frequentava a igreja, fazendo parte das representaçóes teatrais da época na pele do "coxo" que seguia os apóstolos João e Pedro, e sabia recitar de memória alguns capítulos da bíblia.

A descrição de Kahitu feita por Xitu revela um sujeito construído a partir dos encontros e desencontros coloniais, que maneja os diferentes saberes a seu favor, ou seja, ao mesmo tempo que era um "mestre" ferreiro e tradicionalista - funçôes vitais nas antigas sociedades Kimbundu -, sabia ler e escrever o português e era um "bom cristão", dois novos elementos de distinção social trazidos pelo colonizador.

Dessa forma, Kahitu era um mediador cultural, um passeurs culturels (Bénat-Tachot e Gruzinski, 2001), sujeito entre dois mundos, capaz de produzir leituras, interpretaçóes e sínteses no movimento de mão dupla no qual circulam elementos ou fragmentos das culturas em contato (Castro Gomes e Hansen, 2016; Gruzinski, 2001, 2003). Ele articula o local (mestres de oficio e os genealogistas) com o global (uma língua e uma religião de abrangência mundial), aproximando hábitos, práticas, conhecimentos, muitas vezes misturando-os, fazendo com que os mesmos assumam novos significados e novas funçóes. A alegoria que Xitu usa para enfatizar esse papel de tradutor cultural assumido por Kahitu é dizer que ele, como um escritor de cartas da comunidade local, ouvia as histórias em quimbundo e as escrevia em português, ou ainda a expressão "kituta de Deus", usada para denominar Kahitu, evidenciando o surgimento de um novo personagem, híbrido, fruto das relaçôes coloniais.

Xitu continua analisando Kahitu, dizendo que, mesmo paralítico, ele queria ter um lar, desposar 
uma mulher e ver se era ou não viril. Saki, a mais independente das mulheres da aldeia, tornou-se para ele também a mais atraente e a única a quem conseguiria contar os seus desejos. Depois de várias investidas, viu os seios de Saki e, finalmente, tem com ela uma relação sexual, engravidando-a. Depois disso, firmemente pressionada (com surras do pai e conselhos de uma amiga), Saki resolve contar toda a verdade, de que teve uma relação sexual com Kahitu e a certeza de que estava esperando um filho dele e que esse filho seria consagrado à kituta. "O primeiro homem que conheci é o Kahitu, mas o fruto do meu ventre é de kituta, assim penso" (Xitu, 2004c, p. 136).

O caos se instala dentro da sanzala, o feitiço surge, então, como um eixo que poderia explicar o porquê daquilo ter acontecido, pois poderia ser que não se tratasse de um "simples paralítico", mas de um "camuflado feiticeiro perigoso", que usaria do mbanze (uma espécie de amuleto usado no processo de conquista) para seduzir as jovens da aldeia. $\mathrm{O}$ feiticeiro era visto como o "terror da populaçáo", pois ele praticava sobretudo o "mal", escondido e quase sempre à noite. Poderia se transformar em bicho, em coisa ou vegetal. Tornava-se feiticeiro através de uma ação extrema, ou seja, cometer incesto, mesmo com a mãe, matar por feitiço um parente próximo etc. Tinha um coração de tamanho grande, ou mesmo dois coraçóes para assim poder caber neles o "quanto existe de pior". Em Ilundo: divindades e ritos angolanos, Ribas (1958) diz que as ciências do kimbandeiro e do feiticeiro eram diferentes e não podiam ser todas elas designadas pelo nome de feitiço. Diz ainda que, enquanto o kimbanda praticava a umbanda, que significa a "arte de curar" ou ainda "cerimônia ou prática ritual efetuada pelo quimbanda", o feiticeiro praticava a uanga, vista como "malefício", "veneno ou droga nociva" feito por um "ocultista".

Outra hipótese era de que Saki teria engravidado de um "aleijado" como obra de um feitiço feito pelos pretendentes rejeitados por ela. Para alguns membros da sanzala, a kituta viria defender Kahitu, o que poderia ser provado pela existência de grande número de cigarras, que, como "sereias estridentes”, enchiam as árvores naquela manhã. A associação das cigarras com sereias era comum em Angola; ainda no século XVIII, o então governador Francisco Inocêncio de Sousa Coutinho (1764-1772) dizia que Angola era para aqueles que conseguissem resistir às doenças causadas pelo clima da região e para quem soubesse resistir aos cantos das cigarras, as "sereias desses mares" (Pantoja, 1997).

Insone, Kahitu póe-se a questionar se o tribunal de sobas formado tinha alguma autoridade moral para denunciá-lo, sobretudo porque ele, anos antes, tinha se interposto contra um velho que queria se casar com uma moça mais jovem e também porque só viam nele alguma utilidade quando necessitavam de um leitor ou escritor de cartas: "devo ser julgado num Tribunal composto por feiticeiros, gatunos, velhacos, interesseiros, ingratos. Não, não vou, ainda que tenha de ser arrastado" (Xitu, 2004c, p.143). Para ele, se fosse julgado por um chefe do posto, talvez assim aceitasse, mas, como tinha dificuldade de se locomover, não iria até essas autoridades coloniais "pedir justiça”. Assim, Kahitu evidencia um contexto no qual não só os universos religiosos estavam em confronto, mas também os poderes administrativos estabelecidos, sabendo manejá-los de acordo com seus interesses e revelando seus diferentes pertencimentos:

Se de facto sou uma dos enviados da Kituta de Kasadi, como dizia minha mãe, porra, alguma vez na vida esta Kituta me ajudará. Lembro-me quando novo e frequentava a Igreja e na cena dos textos bíblicos que se referiam ao paralítico eu gritava: "Jesus, filho de David, tenha misericórdia de mim!". Houve momentos que sentia a impressão de que os pés estavam a querer mexer-se. Mas fiquei desiludido, não obstante a fé, a fé que o mano Pedro, fanático, recomendava. Textos de um passado e de um povo que a história registrou. Se tu és Kituta mesmo, ao menos que tenha pena de mim... (Xitu, 2004c, p. 144).

No momento de grande angústia e confusão mental, os repertórios em alcance são acionados (o Kimbundu e o cristão), mas o que sobressai é o seu pertencimento ao mundo tradicional. Nessa situação confusa, ainda mais com as ofensas do pai de Saki, Kahitu pega debaixo de sua cama uma lati- 
nha com veneno de matar gafanhotos, visto existir naquele momento uma praga, toma o seu conteúdo, contorce-se de dor, e, mesmo depois de alguns vomitórios, não resiste e morre. Previsto para ser enterrado no mesmo dia, isso náo ocorre devido a uma forte chuva que começara.

As árvores são sacudidas impiedosamente, os cabritos e ovelhas, do pasto, correm entre berros para os currais. Algumas casas de colmo cobertas a capim são estapadas [?] e o capim levado em reboliço nas alturas. Então, desaba um aguaceiro forte acompanhado de vento e trovoadas aterradoras (Xitu, 2004c, p. 147).

A chuva continuou, ameaçadora, com raios caindo e provocando incêndios em várias cabanas. "As baixas transbordavam de água de forma tal que nunca foi vista na sanzala", além disso, "os raios desenhavam figuras sinistras na noite profundamente escura", "a terra cheirava a pólvora" (Xitu, 2004c, p. 148). Estaria a kituta punindo a população local pela morte do seu filho? "Seria o Kahitu ou a vingança de Kahitu? Cochichavam aqueles que ainda tinham coragem de o fazer" (p. 148). Mas antes, pelos lados do Madimu e de Zenca do Golungo, o céu já estava carregado de grandes nuvens brancas, um prenúncio de que choveria fortemente dentro de alguns dias. Como explicar aquelas chuvas? Vingança da kituta ou uma precipitação natural? São essas as questóes postas pelo narrador/Xitu.

Naquela situação, os maiores kimbandas da região se reuniram para uma sessão de magia. Visando atrair os raios, fizeram encantamentos, preces, cantos, espalharam grãos de milho ao chão. Os raios diminuíram, mas a chuva continuou torrencial. E, nesse cenário, a "vingança da kituta" fez uma vítima, Saki, justamente aquela com quem Kahitu tivera a relação, que perde o filho; "o maior estrondo do tempo que ensurdece, reboa, reboa, reboa; fulminou casas, passou pelo quarto da Saki, que é atirada à distância da cama, jazendo ao chão com uma abundante hemorragia vaginal" (Xitu, 2004c, p. 148). Mais três pessoas também foram atingidas pelos raios, e só no terceiro dia é que Kahitu foi enterrado.

A sanzala sofreu por anos os efeitos da chuva.

\section{Consideraçóes finais}

Através da análise de Vozes na sanzala (Kahitu), percebemos que a articulação social da diferença Kimbundu/português foi uma negociação complexa, em andamento, que procurou conferir autoridade aos hibridismos culturais que emergiram naquele momento de transformação histórica, ocasionada pela maior presença missionária e europeia, sendo tais hibridismos uma forma pela qual as pessoas daquele contexto lidaram com as mudanças modernas, muitas das quais traumáticas.

$\mathrm{Na}$ sanzala descrita por Xitu, conciliar visóes de mundo conflitantes, e até mesmo antagônicas, fazia parte do processo geral de acomodação em um contexto no qual os povos Kimbundu e português se ligaram uns aos outros pela imposição da situação colonial. Assim, podemos entender as costuras e articulações da sanzala e do universo mítico-religioso descrito por Xitu como um amplo processo de misturas e mestiçagens onde a manutenção de determinados elementos da cultura tradicional Kimbundu funcionava como uma reação de sobrevivência e resistência a uma situação instável e imprevisível devido à presença missionária e ao questionamento, mas também reafirmação, das antigas tradiçôes locais.

Ao fazer uso dos saberes tradicionais (o ferreiro) e do novo/moderno (a escola), Kahitu revela-se capaz de entender os mecanismos detentores de força e valor presentes naquele novo universo social, sabendo fazer o uso correto deles; por essa razão, naquela situação desigual com maior poder dos saberes ocidentais, a escola era mais atraente do que a profissão de ferreiro.

Por outro lado, a cultura Kimbundu, em situações de contato (e de subordinação) com o universo europeu, náo se perdeu, mas adquiriu uma nova função, a de acentuar o pertencimento e a identidade dos membros da aldeia. Assim, se o culto aos gênios da natureza, as crenças nos kilambas e kimbandas e a leitura do mundo visível e invisível como integrados se tornaram algo residual, e sujeitos a um amplo processo de hibridismo, mistura e mestiçagem, mantiveram-se, por outro lado, irredutíveis, inegociáveis dentro da sanzala. 


\section{Notas}

1 Desde, pelo menos, o século XVI, os povos vizinhos do Kongo, que mantiveram uma relaçáo de conflito e dominação sobre os Kimbundu, designavam esse povo de ambundo (ambundu ou mbundu), que significava "negro", "escravo" e/ou "selvagem". A junção ambundo-quimbundo, feita também pelos portugueses, ainda muito usual na historiografia brasileira sobre o tema, significa "negro/escravo/selvagem que falam quimbundo". Em grande parte, essa definição já presente em documentos do século XVI, foi reiterada e amplamente divulgada pelo etnólogo José Redinha (1975), que, com sua extensa produção sobre os grupos étnicos angolanos, serve até hoje como a principal referência para denominar, a nosso ver erroneamente, os povos dessa região. Essas informaçôes se baseiam em Ruy Carvalho (2008). Preferimos seguir as sugestóes dadas por Virgílio Coelho (2010) e por Maria da Conceição Neto (2003), que utilizam em seus textos sempre a expressão falantes de Kimbundu.

2 De acordo com Manuela Carneiro da Cunha, "a cultura original de um grupo étnico, na diáspora ou em situaçôes de intenso contato, não se perde ou se funde simplesmente, mas adquire uma nova função, essencial e que se acresce às outras, enquanto se torna cultura de contraste: este novo princípio que a subtende, a do contraste, determina vários processos" (Carneiro da Cunha, 1986, p. 99). Assim sendo, essa cultura original se acentua, se torna mais visível, mas também mais simples e rígida.

\section{BIBLIOGRAFIA}

BÉNAT-TACHOT, Louise \& GRUZINSKI, Serge. (2001), Passeurs culturels: mécanismes de métissasge. Paris, Presses Universitaires de Marne-la-Vallée, Éditions de la Maison des Sciences de L'Homme.

CAMARA CASCUDO. (2000), Dicionário do folclore brasileiro. São Paulo, Global.

CARNEIRO DA CUNHA, Manuela. (1986), "Etnicidade: da cultura residual mas irredutível", in Antropologia do Brasil, São Paulo, Brasiliense.
CARVALHO, Ruy Duarte de. (1989), Ana e Manda os filhos da rede - identidade coletiva, criatividade social e produção da diferença cultural: um caso muxiluanda. Lisboa, IICT.

. (2008), "Para a definição de uma área sócio-cultural Ambundu", in A câmara, a escrita e a coisa dita..., Lisboa, Cotovia.

CASTRO GOMES, Angela de \& HANSEN, Patrícia Santos. (2016), Intelectuais mediadores: práticas culturais e ação política. Rio de Janeiro, Civilização Brasileira.

COELHO, Virgílio. (2010), Os túmúndòngò, os "gênios" da natureza e o kilámba: estudos sobre a sociedade e a cultura quimbundo. Luanda, Kilombelombe.

"Imagens, símbolos e representações quiandas, quitutas, sereias!: imaginários locais, identidades regionais e alteridades: reflexões sobre o quotidiano urbano luandense na publicidade e no universo do marketing". NGOLA - Revista de Estudos Sociais (ASA). 1 (1): 127-192.

CONCEIÇÃO, Simone Ribeiro. (2010), "Missossos e makas: o inventário dos costumes angolanos na escrita de Óscar Ribas e Uanhenga Xitu", in A. Vieira et al., África: passado e presente. Niterói, EdUFF.

CONCEIÇÃO NETO, Maria. (2003), "Breve introdução histórica", in M. C. Medina, Processos politicos da luta pela independência, Luanda, Faculdade de Direito da Universidade Agostinho Neto.

COSTA E SILVA, Alberto da. (1998), A manilha e o libambo. São Paulo, Nova Fronteira.

DIAS, Jill R. (1994), "Mudanças nos padrōes de poder no hinterland de Luanda: o impacto da colonização sobre os Mbundu”. Penélope, 14: 43-91.

FENTRESS, James \& WICKHAM, Chris. (1992), Memória social. Lisboa, Teorema.

FONSECA, Maria Nazareth Soares. (2010), "Literatura e 'arquivos da memória': negociação e dispersão dos sentidos", in C. T. Secco, M. T. Salgado e S. R. Jorge (orgs.), África, escritas literárias, Rio de Janeiro/Angola, Editora da UFRJ/UEA (União dos Escritores Angolanos).

FONSECA, Mariana B. (2015), Nzinga Mbandi e as guerras de resistência em Angola, século XVII. Belo Horizonte, Mazza. 
GESCHIERE, Peter. (2006), "Feitiçaria e modernidade nos Camaróes: alguns pensamentos sobre uma estranha cumplicidade". Revista Afro-Ásia, 34: 9-38.

GRUZINSKI, Serge. (2001), O pensamento mestiço. São Paulo, Companhia das Letras.

. (2003), A colonização do imaginário: sociedades indígenas e ocidentalização no México espanhol, séculos XVI-XVIII. São Paulo, Companhia das Letras.

HAMPATE BA, Amadou. (2007), "A tradição viva”, in J. Ki-Zerbo, História Geral da Africa. Vol. I: Metodologia e pré-história da África, São Paulo, Cortez.

HEINTZE, Beatriz. (1998), Angola nos séculos XVI e XVII. Luanda, Kilombelombe.

MACEDO, Tania. (2008), "A oratura em Angola", in __ Luanda, cidade e literatura, São Paulo, Editora da Unesp.

MACEDO, Tania \& CHAVES, Rita. (2007), "Tradição oral", in _ Literaturas de língua portuguesa: marcos e marcas - Angola, São Paulo, Arte e Ciência.

MATEUS, Dalila Cabrita. (2006), Memórias do colonialismo e da guerra. Porto, Ediçôes ASA.

MESSIANT, Christine. (1998), "Protestantismes en situation coloniale: Quelles marges?”. Lusotopie, 5: 245-256.

NETO, Akiz. (2009), Poeticidade no discurso prosaico de Wanyenga Xitu. Luanda, UEA (União dos Escritores Angolanos).

PANTOJA, Selma. (1997), "Luanda: relaçóes raciais e de gênero", in Atas da II Reuniāo Internacional de História da África, Rio de Janeiro, vol. 1, p. 77.

PAREDES, Margarida. (2010), "Deolinda Rodrigues, da família Metodista à família MPLA, o papel da cultura na política”. Cadernos de Estudos Africanos, 20: 11-26.

PÉLISSIER, René. (1978), La colonie du Minotaure: nationalisme et révoltes en Angola (19261961). Orgeval, Pélissier.

PRATT, Mary Louise. (1999), Os olhos do império: relatos de viagens e transculturaçâa. Bauru, Edusc.

REDINHA, José. (1975), Sincretismos religiosos dos povos de Angola. Luanda, Instituto de Investigação Científica de Angola.
RIBAS, Oscar. (1958), Ilundo: divindades e ritos angolanos. Luanda, Museu de Angola.

. (2002), Temas da vida angolana e suas incidências: aspectos sociais e culturais. Luanda, Edições Chá de Caxinde.

. (2009 [1969]), "Elucidário", in Uanga (feitiço), Luanda, Mercado das Letras.

SANTOS, Eduardo dos. (1969), Religióes de Angola. Lisboa, Junta de Investigação do Ultramar.

TURNER, Victor. (2005), Floresta de simbolos: aspectos do ritual Ndembu. Niteroi, EdUFF.

XITU, Uanhenga. (1978), Manana. Lisboa, Ediçóes 70 .

. (1979), Maka na sanzala. Lisboa, Edições 70 .

(1984a), Os discursos do Mestre Tamoda. São Paulo, INL.

(1984b), Palestra, in Os discursos do "mestre" Tamoda, Luanda, UEA (União dos Escritores Angolanos)/Inald (Instituto Nacional do Livro Didático).

(1991a). Entrevista, in M. Laban, Angola: encontro com escritores, Porto, Fundação Eng. António de Almeida.

. (1991b), O ministro. Luanda, UEA (Uniāo dos Escritores Angolanos).

. (2004a), Bola com feitiço. Luanda, Edições Maianga.

. (2004b), Entrevista, in A. L. de Sá, A. Cristóvão e I. Cori, Pessoas com quem conversar, Luanda, UEA (União dos Escritores Angolanos).

. (2004c), Vozes na sanzala (Kahitu): contos. Luanda, Ediçóes Maianga [ $1^{\text {a }}$ ediçấo em $1976]$.

. (2006). Entrevista, in D. C. Mateus, Memórias do colonialismo e da guerra, Porto, Edições ASA.

. (2014), Depoimento: "Histórias de mais velho". O Chá, 9 (2): 18 [Original em: JL Jornal de Letras Artes e Ideias, Lisboa, 12 ago. 1998]. 


\section{UNIVERSO MÍTICO-RELIGIOSO KIMBUNDU E TRÂNSITOS CULTURAIS EM UANHENGA XITU}

\section{Washington Santos Nascimento}

Palavras-chave: Kimbundu; Universo mítico-religioso; Uanhenga Xitu; Memória; Literatura.

Este artigo tem por propósito fazer uma discussão sobre o universo mítico-religioso Kimbundu (sobretudo os gênios da natureza e sacerdotes), de fins do século XIX até meados do século XX. Para tanto, analisaremos a obra Vozes na sanzala: Kahitu, do escritor angolano Wanyenga Xitu (Uanhenga Xitu, na versão aportuguesada), entendida enquanto uma memória social dos AkwaKimbundu, procurando, desta forma, discutir os processos de misturas, mestiçagens e pertencimentos.

\section{KIMBUNDU MYTHICAL- RELIGIOUS UNIVERSE AND CULTURAL TRANSITIONS IN UANHENGA XITU}

\section{Washington Santos Nascimento}

Keywords: Kimbundu; Mythical-religious universe; Uanhenga Xitu; Memory; Literature.

This article aims to make a discussion of Kimbundu mythical-religious universe (especially the expert of nature and the priests), from the late nineteenth to midtwentieth century. I will make this discussion through the analysis of the work Voices in sanzala: Kabitu by the Angolan writer Wanyenga Xitu (Uanhenga Xitu in Portuguese) that is understood as a social memory of AkwaKimbundu, thus seeking to discuss the processes of mixtures, miscegenation and belongings.

\section{L'UNIVERS MYTHIQUE- RELIGIEUX KIMBUNDU ET LES ÉCHANGES CULTURELS DE WANYENGA XITU}

\section{Washington Santos Nascimento}

Mots-clés: Kimbundu; Univers mythique-religieux; Uanhenga Xitu; Mémoire; Littérature.

Cet article propose une discussion sur l'univers mythique et religieux Kimbundu (en particulier les esprits de la nature et les prêtres), de la fin du XIXe siècle jusqu'au milieu du XXe siècle. Pour cela, nous examinerons l'œuvre Vozes na sanzala: Kahitu de l'écrivain angolien Wanyenga Xitu (Uanhenga Xitu, suivant la version portugaise), comprise comme une mémoire sociale des AkwaKimbundu, qui se propose de discuter les processus de mélanges, de métissages et d'appartenance. 